
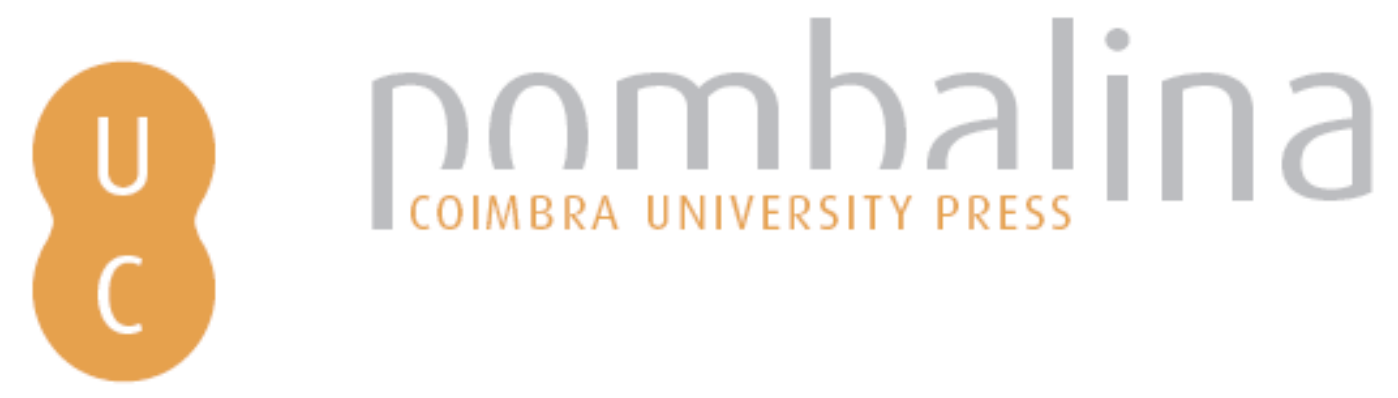

\title{
Inventarios post-mortem, cultura material y consumo en Léon durante la Edad Moderna
}

\author{
Autor(es): $\quad$ Bartolomé Bartolomé, Juan M. \\ Publicado por: Imprensa da Universidade de Coimbra \\ URL \\ persistente: URI:http://hdl.handle.net/10316.2/31587 \\ DOI: DOl:http://dx.doi.org/10.14195/978-989-26-0201-1_8 \\ Accessed : $\quad$ 26-Apr-2023 13:47:01
}

A navegação consulta e descarregamento dos títulos inseridos nas Bibliotecas Digitais UC Digitalis, UC Pombalina e UC Impactum, pressupõem a aceitação plena e sem reservas dos Termos e Condições de Uso destas Bibliotecas Digitais, disponíveis em https://digitalis.uc.pt/pt-pt/termos.

Conforme exposto nos referidos Termos e Condições de Uso, o descarregamento de títulos de acesso restrito requer uma licença válida de autorização devendo o utilizador aceder ao(s) documento(s) a partir de um endereço de IP da instituição detentora da supramencionada licença.

Ao utilizador é apenas permitido o descarregamento para uso pessoal, pelo que o emprego do(s) título(s) descarregado(s) para outro fim, designadamente comercial, carece de autorização do respetivo autor ou editor da obra.

Na medida em que todas as obras da UC Digitalis se encontram protegidas pelo Código do Direito de Autor e Direitos Conexos e demais legislação aplicável, toda a cópia, parcial ou total, deste documento, nos casos em que é legalmente admitida, deverá conter ou fazer-se acompanhar por este aviso.

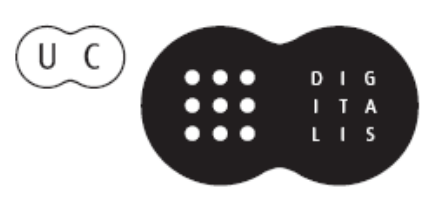


Isabel dos Guimarães Sá Máximo García Fernández (directores)

\section{PORTAS ADENTRO comer, vestir, habitar} (ss. XVI-XIX) 


\title{
INVENTARIOS POST-MORTEM, CULTURA MATERIAL Y CONSUMO EN LEÓN DURANTE LA EDAD MODERNA
}

\author{
JuAN M. BARTOLOMÉ BARTOLOMÉ \\ Departamento de Historia Moderna ${ }^{1}$ \\ Universidad de León (España)
}

Los inventarios post-mortem, a los que se pueden añadir las escrituras de división de bienes (denominadas partijas) que incluyen también un inventario post-mortem previo de los bienes, constituyen la fuente principal utilizada en este tipo de trabajos que hemos realizado sobre las condiciones vida, pautas de consumo y la cultura material en León durante la dad Moderna, particularmente el siglo XVIII y primera mitad del XIX.

Consideramos que queda lejos de los objetivos de esta comunicación volver a retomar la extensa relación de historiadores más partidarios ${ }^{2}$ o contrarios ${ }^{3}$

${ }^{1}$ El presente trabajo se enmarca en el proyecto de investigación «Cultura material, consumo, moda e identidades sociales. Mujer, vestido y apariencias en Castilla y en León durante el Antiguo Régimen (S. XVI-XIX) financiado por la JCYL.

${ }^{2}$ En el trabajo de A. Eiras Roel, «Tipología documental de los protocolos gallegos», en $L a$ Historia social de Galicia en sus fuentes de protocolos, Santiago de Compostela, Universidad de Santiago, 1981, pp. 28-29, existe una información bibliográfica sobre esta cuestión.

${ }^{3}$ Entre los detractores se pueden citar a M. Garden en su estudio sobre Lyon et les lyonnais au XVIII siècle, París, Flammarion, 1975, donde rechazaba, en principio, los inventarios postmortem debido a tres motivos: primero, porque se derivaban de un acto judicial y sólo se realizaban cuando existía problemas particulares entre los herederos. Segundo, sólo ofrecen una descripción parcial de las fortunas, ya que únicamente los bienes muebles son el objeto de mayor atención. Y finalmente, por su naturaleza concierne a personas de elevada edad, con lo que la mayoría de ellas han abandonada ya su actividad. En los últimos años, han surgido también objeciones a la hora de su utilización para el estúdio del consumo familia, etc., centradas en problemas metodológicos (ver Bartolomé Yun Casalilla, «Inventarios postmortem, consumo y niveles 
de este tipo de fuente desde que la historiografía francesa descubriese sus posibilidades. Sólo señalar que en España, desde los pioneros años 1980 donde el profesor A. Eiras hablaba de su importancia para la historia social ${ }^{4}$, han sido una fuente básica tanto para la historia rural, urbana, como para la historia social, destacando en este sentido los realizados sobre la burguesía española del siglo $\mathrm{XVIII}^{5}$ y de forma más reciente los centrados en la historia de la familia ${ }^{6}$ y las condiciones de vida, pautas de consumo, y, en definitiva, en la cultura material, etc. ${ }^{\text {. }}$

Centrándonos en el caso leonés, podemos afirmar que los inventarios postmortem presentan muchas más ventajas que inconvenientes, ya que, en primer lugar, en general no se derivan de un acto judicial y son, por lo tanto, una escritura sistemática a nivel cronológico, aunque no tan abundante como desearíamos. En segundo lugar, es bastante universal, ya que encontramos inventarios post-mortem o partijas de todos los grupos sociales, incluso con escasos niveles de riqueza patrimonial, lo cual nos permite abordar estudios comparativos. En tercer lugar, dado su carácter básicamente post-mortem nos aportan datos tanto de los comienzos como del final de sus trayectoria vitales. Y finalmente, en una buena proporción se incluyen todos los bienes tanto raíces y semovientes como mobiliarios y tasados. Se trata de un precio de referencia pero que como es de suponer resulta de gran valor. En cambio, como inconvenientes, aparte de su escasez y de algunos problemas, no muchos, de ocultación de bienes por parte de los viudos, sólo podemos mencionar, por una parte, la parca información sobre las calidades de los bienes mobiliarios, que se acentúan cuando se refieren a los textiles y sobre todo a las librerías. Y, por otra parte, la ausencia de ropa, sobre todo la destinada a vestir el cuerpo, la personal, que nos induce a pensar bien en una venta previa de la misma, antes de que se efectúe el inventario, para correr

niveles de vida del campesinado del antiguo régimen (Problemas metodológicos a la luz de la investigación internacional), VII Congreso de Historia Agraria, Salamanca, 1997, pp. 46-55.

${ }^{4}$ Ver trabajo ya citado de A. Eiras Roel, ob. cit., p. 28.

${ }^{5}$ Sobre todo la burguesía conectada con el mundo del comercio y las finanzas. Ver trabajos de A. García Baquero González, Cádiz y el Atlántico (1717-1778), Sevilla, Diputación de Cádiz, 1988; R. Franch Benavent, El capital comercial valenciano en el siglo XVIII, Valencia, Facultad de Geografía e Historia, Facultad de Historia Moderna, 1989; A. M ${ }^{a}$ Azcona Guerra, Comercio y comerciantes en la Navarra del siglo XVIII, Navarra, Gobierno de Navarra, 1996; A. Angulo Morales, Del éxito en los negocios al fracaso del Consulado: la formación de la burguesía mercantil de Vitoria (1670-1840), Bilbao, Universidad del País Vasco, 2000.

${ }^{6}$ D. Martínez López, Tierra, herencia y matrimonio. Un modelo sobre la formación de la burguesía agraria andaluza (Siglos XVIII-XIX), Jaén, 1996; Juan M. Bartolomé Bartolomé, Familias de comerciantes y financieros en la ciudad de León (1700-1850). En prensa.

${ }^{7}$ Grupo de trabajo coordinado por Bartolomé Yun Casalilla, «Consumo y comercialización de textiles en Castilla y Cantabria, 1750-1914». Juan M. Bartolomé Bartolomé, El tránsito al crecimiento económico moderno en León. Condiciones de vida y pautas de consumo en La Bañeza y Astorga, León, Universidad de León, 2004. 
con parte de los gastos del entierro, o bien en un reparto de la misma entre los seres más estimados a nivel afectivo.

Ahora bien, a pesar de las virtudes señaladas a nivel general hemos de reconocer que en su utilización como fuente para el estudio del consumo familiar los problemas metodológicos siguen existiendo, y en concreto éstos se podrían centrar en tres: por un lado, el que consideramos de mayor relevancia, tal como ha señalado J. De Vries, reflejan el «stocks» de un determinado producto y no su «flujo», es decir no nos informan, por lo menos tal como desearíamos, de los niveles de reposición de los artículos ${ }^{8}$. Por otro lado, el problema de la representatividad a nivel social, dada la tendencia hacia patrimonios altos o medianos y la escasez de inventarios de los grupos sociales más desfavorecidos a nivel económico 9 . Y finalmente, también se han planteados serias dudas sobre si el cuerpo general de bienes reflejado en el inventario post-mortem constituye una medida realmente válida de la riqueza del individuo dada la diversidad existente en las fuentes de ingresos de las economías familiares campesinas ${ }^{10}$.

De todas formas, al margen de la problemática y las limitaciones que plantea la fuente, en los momentos presentes hemos conseguido acercarnos, utilizando fundamentalmente los inventarios post-mortem, al estudio de los niveles de riqueza patrimoniales, riqueza mobiliaria, condiciones de vida y pautas de consumo, etc., de una muestra bastante amplia de la estructura social leonesa (burguesía comercial de la ciudad de León y de Astorga y La Bañeza, artesanos, campesinos, etc.,) durante el siglo XVIII y primera mitad del XIX. Además, hemos intentado adentrarnos en su análisis no sólo cuantitativo sino cualitativo, prestando especial interés a las mutaciones derivadas de las modas o el consumo vicario y que pudiesen reflejarse en cambios en las pautas de consumo, particularmente de los textiles ${ }^{11}$.

No obstante, nuestro objetivo no es presentar todas las conclusiones, debido a problemas de espacio, sino más bien centrarnos en dos grupos sociales, burguesía comercial y financiera de la ciudad de León y campesinado de la comarca

${ }^{8} \mathrm{~J}$. De Vries, «Between purchasing power and the world of goods: understanding the household economy in early modern Europe», en J. Brewer, R. Porter (eds.), Consumption and the World of Goods, Londres-Nueva York, Routledge, pp. 206-227.

${ }^{9}$ Es lo que considera T. Wijsenbeck en su estudio para los Países Bajos, a pesar de que de en Holanda el inventario se hacía entre los grupos sociales más desfavorecidos como una iniciativa pública para preservar los intereses de los herederos, «Delf in the eighteenth century», en A. Van der Woude y A. Schuurman (eds.), Probate inventories. A new source for the historical study of wealth, material culture and agricultural development, Utrecht, HES Publishers, 1980, pp. 157-176.

${ }^{10} \mathrm{~L}$. Weatherill, «The meaning of consumer behaviour in late seventeenth -and early eighteenth- century England», en J. Brewer y R. Porter (eds.), ob. cit., pp. 206-227.

${ }^{11}$ Juan M. Bartolomé Bartolomé, «El consumo de textiles en León (1700-1860)», en Revista de Historia Moderna. Anales de la Universidad de Alicante, n. 21, Alicante, 1982, pp. 473-501; Ibidem., El tránsito al crecimiento económico... 
de Sahagún, elegidos por su distinto nivel de riqueza económica, su emplazamiento urbano y rural, y analizar la cultura material y las pautas de consumo a lo largo del siglo XVIII y la primera mitad del siglo XIX. Además, el estudio resulta más enriquecedor debido a la heterogeneidad del propio campesinado terrracampino, lo cual nos permite a su vez hacer comparaciones del mismo y con el resto del campesinado leonés.

\section{CONDICIONES DE VIDA Y PAUTAS DE CONSUMO DE LA BURGUESÍA COMERCIAL Y FINANCIERA DE LA CIUDAD DE LEÓN}

Los valores medios del activo patrimonial de la burguesía comercial se sitúan en 504.091 reales, los cuales una vez descontadas las deudas, el pasivo (que supone un 8\%), quedan líquidos 463.890 reales de media. Se trata, por lo tanto, de unos valores ligeramente superiores a los del resto de la burguesía leonesa $^{12}$, pero todavía alejados de la burguesía interior comercial vitoriana o extremeña ${ }^{13}$ y a años luz de la de los puertos como la valenciana o gaditana ${ }^{14}$. Incluso, la burguesía comercial financiera de nuestra muestra ofrece unos líquidos patrimoniales, 893.883 reales, muy alejados de nuevo de la burguesía gaditana e incluso de los comerciantes banqueros extrememos ${ }^{15}$.

Patrimonios que no han sido fruto de la herencia sino que más bien han sido forjados con el esfuerzo y el trabajo diario de los negocios. Así, del estudio de ocho casos de la burguesía dedicada exclusivamente al comercio los bienes

${ }^{12}$ En La burguesía maragata sólo tres casos de un total de dieciséis superan dicha cantidad. La burguesía de la provincia, bañezana, astorgana y berciana, del siglo XVIII está también muy por debajo y sólo en El Bierzo en la primera mitad del siglo XIX se aproximan a las medias señaladas. L. Rubio Pérez, La burguesía maragata, León, Universidad de León, 1995; Idem, «La burguesía mercantil leonesa en el siglo XVIII. Acumulación de capital y actitudes tradicionales», en Revista Estudios Humanísticos, n. 13, Universidad de León, 1991, pp. 227-264; Juan M. Bartolomé Bartolomé, Vino y viticultores en El bierzo. Sociedad y estructuras económicas durante el siglo XVIII, León, Universidad de León, 1996; Idem, La hegemonía de una nueva burguesía en El Bierzo (1800-1850), León, Universidad de León, 2000.

${ }^{13}$ En Vitoria el porcentaje de casas mercantiles con niveles líquidos por debajo de los 500.000 reales es del 58,3\%. A. Angulo Morales, ob. cit., p. 297.

${ }^{14}$ En Extremadura de cinco casos sólo uno está por debajo con un líquido de 189.974 reales M. A. Melón Jiménez, Los orígenes del capital comercial financiero en Extremadura. Compañías de comercios, comerciantes y banqueros de Cáceres (1773-1836), Badajoz, Diputación Provincial de Badajoz, 1992, pp. 119-120.

En Valencia por debajo de las 35.000 libras (que vendrían a equivaler aproximadamente a 500.000 reales) se sitúan el 37,73\% de los inventarios analizados. R. Franch Benavent, ob. cit., p. 38 .

En Cádiz, con una orientación más financiera que comercial, las estimaciones rondaban entre 3.570.000 y unos 14.280.000 reales. A. García Baquero González, ob. cit., pp. 510-511.

${ }^{15}$ M. A. Melón Jiménez, ob. cit., p. 139. 
gananciales suponen un 77,2\% del total del activo patrimonial y sólo un 27,8\% son los bienes aportados por los esposos, bien dotales o parafernales. De éstos predominan los que han llevado a la unidad familiar los esposos, 61,8\%, frente al $38,2 \%$ de las esposas.

En las familias de la burguesía comercial con orientación más financiera también son patrimonios conseguidos con esfuerzo y los quehaceres diarios más que heredados, ya que en una valoración global el 65,5\% del activo patrimonial corresponde a bienes gananciales quedando para los dotales y parafernales el $34,5 \%$ restante.

Si pasamos al estudio más pormenorizado de la estructura interna de esta riqueza patrimonial, nos encontramos con que lógicamente son los bienes mobiliarios los que tiene una mayor peso, el 74,5\% en la burguesía comercial y el $58,9 \%$ en la financiera, lo cual está en conexión directa con la relevancia dentro de los mismos de los conceptos o partidas vinculadas a la actividad mercantil o financiera.

Ahora bien, de todos los bienes que componen la riqueza mobiliaria nos interesan para nuestro estudio de la cultura material los siguientes: decoración de la casa (objetos religiosos), mobiliario de la casa, útiles de cocina (menaje de loza fina), ropa personal, ropa cama, ropa casa, objetos de oro y plata y libros. Así, nos encontramos con que estos bienes representan unos porcentajes muy bajos, entre un $6 \%$ para la burguesía comercial y un $4,2 \%$ para la comercial y financiera de la riqueza patrimonial mobiliaria. Aún así son porcentajes ligeramente superiores a los de la burguesía gaditana y similares en la burguesía comercial y financiera a la sevillana ${ }^{16}$.

Desde un punto de vista más cuantitativo en la burguesía comercial la valoración más alta de estos bienes, con un 36,6\%, corresponde a los objetos de oro y plata, joyas, alhajas, tanto de los orientados al uso personal como los de cubertería. Indudablemente, esta alta presencia de objetos de oro y plata, tesaurización, guarda una estrecha relación con el hecho de que al ser la actividad económica principal el mundo incierto del comercio, era necesario que la familia tuviese objetos de valor que no sufriesen las alteraciones monetarias y sirviesen para poder salir de momentos de crisis del negocio frente a las deudas o a impagos puntuales, ya que se podían convertir fácilmente en dinero ${ }^{17}$. Además, tampoco debemos obviar que estos objetos tan preciados exteriorizan el éxito económico y social de la casa y una forma más de ingresar en una posición social de privilegio.

${ }^{16}$ M. Bustos Rodríguez, Cádiz en el sistema atlántico. La ciudad, sus comerciantes y la actividad mercantil (1650-1830), Madrid, Sílex, 2005, p. 238; A. García Baquero González, La carrera de Indias: suma de la contratación y océano de Negocios, Sevilla, Algaida Editores, 1992, p. 309.

${ }^{17}$ Es lo mismo que sucede con la burguesía vitoriana, donde incluso Alberto Angulo Morales incluye estos objetos de oro y plata junto con el dinero líquido. A. Angulo Morales, $o b$. cit., p. 318. 
En segundo lugar, con un porcentaje muy próximo al anterior, un 35,7\%, figura la tasación de los textiles, destacando dentro de los mismos la ropa de la cama sobre la destinada a la vestimenta personal y a la de casa. Esta fuerte presencia de los textiles, que en este caso se atenúa por la circunstancia particular ya analizada de los objetos de oro y plata, es similar a los demás grupos sociales y sobre todo a la burguesía de Vitoria ${ }^{18}$.

Los restantes bienes que nos adentran en las condiciones de vida presentan una valoración más inferior. Es lo que sucede tanto con el mobiliario de la casa, escaparates, arcas, escritorios, cómodas, canapés, etc., que se sitúa en tercer lugar, pero tan sólo con un 12,3\%, como con los útiles y menaje de la cocina, un $9,3 \%$. Y finalmente, los objetos destinados a decorar las estancias de la casa, cuadros, espejos, etc., sólo tendrán una valoración del 2,4\% y los libros del 3,7\% ${ }^{19}$.

Si descendemos a un estudio más cualitativo y dinámico de estos bienes nos encontramos con una relevante información sobre la cultura material, que incluso nos introduce en el interesante campo de las pautas de consumo de la burguesía comercial. Así, en los objetos de oro y plata se aprecia como frente al mayor número de ellos dedicados en el siglo XVIII a objetos de cubertería de la casa, en cambio en la primera mitad del siglo XIX son más abundantes y de mayor valoración los destinados al adorno personal, collares, pendientes, colgantes, etc. ${ }^{20}$. Esta tendencia nos lleva a considerar que las familias burguesas ya asentadas, habiendo logrado ya el éxito en los negocios, tratan de emular los comportamientos de los grupos sociales, en este caso la nobleza, a los que ya han conseguido casi asimilarse.

En los textiles, el predomino observado a nivel de valoración de la ropa de la cama es más propio del setecientos. En cambio, en la primera mitad del siglo XIX es la ropa destinada a vestir el cuerpo, la personal, la que adquiere una mayor importancia, lo cual estaría de nuevo conectado con la mayor inclinación a la ostentación y a la exteriorización social de la riqueza, dentro de un proceso de emulación o consumo vicario de las modas y tendencias de la nobleza ${ }^{21}$.

${ }^{18}$ Dentro del ajuar el agregado de mayor valor se centraba en la ropa y el elemento más llamativo era la cama por el múltiple y caro ropaje que se necesitaba para conformarla. Ibidem, p. 176.

${ }^{19}$ Aunque la presencia de libros que figuran en los inventarios es generalmente nula y sólo en tres casos de los analizados, de los cuales dos de ellos corresponden a la familia FernándezChicarro, encontramos libros, de temática preferentemente religiosa.

${ }^{20}$ Es lo que sucede, por ejemplo, con la tercera generación de la familia FernándezChicarro, don José Fernández Chicarro y doña Rosa Alonso, ya que en el inventario que se realiza tras el fallecimiento del esposo, en 1848, los objetos de oro y plata de uso personal (cadenas, collares, anillos, pendientes, relojes de bolsillo, piedras preciosas de esmeralda y rubíes, etc.), son tasados en 7.299 reales frente a los 4.685 reales de la cubertería. Archivo Histórico Provincial del León (A.H.P.L.), Félix de las Vallinas, Caja 1137.

${ }^{21}$ Así, en el inventario del rico comerciante catalán afincado en la plaza leonesa don Ramón Selva las valoraciones más altas de los textiles son las dedicadas a vestir el cuerpo por encima de la ropa de la cama. Id., Ildefonso García Álvarez, Caja 1167. 
Además, ya desde el último tercio del siglo XVIII observamos cambios en la pautas de consumo de los textiles que se aprecian, por una parte, en la llegada de la nueva fibra textil, el algodón y sus derivados, frente a la predominante lana o lino, de forma más generalizada en la ropa personal ${ }^{22}$ que en la de cama $^{23} \mathrm{o}$ casa $^{24}$. Y por otra parte, en la introducción de las nuevas prendas de vestir tanto femeninas (vestidos, etc.) como particularmente masculinas (chaquetas, chalecos y pantalones), elaboradas preferentemente con la nueva materia prima más barata e innovadora ${ }^{25}$. Estas nuevas tendencias en el consumo de textiles se reforzarán en la primera mitad del siglo XIX, siguiendo la misma trayectoria que la marcada por la bibliografía comparativa que se ha ocupado de este interesante tema del consumo ${ }^{26}$.

Sorprende, aunque es una tendencia generalizada ${ }^{27}$, que el mobiliario de la casa se sitúe en valoración por debajo de la ropa personal. Esta escasa tasación no eran tanto debida a la abundancia de piezas como al reducido valor de las mismas, ya que al igual que la burguesía comercial vitoriana la alta profusión de muebles tradicionales (mesas, sillas, arcas, baúles, bufetes, archivos, etc.) dejaban poco espacio habitable en las estancias ${ }^{28}$. Lógicamente se imitaban también las modas de la nobleza, pero las novedades en el mobiliario tendrán que esperar a la primera mitad del siglo XIX ${ }^{29}$, que es donde ya aparecerán de forma significativa las cómodas ${ }^{30}$, armarios ${ }^{31}$, escritorios, canapés, tocadores, etc., reflejando

${ }^{22}$ En la familia Casado-Valladolid en su inventario de finales del siglo XVIII figurarán prendas tradicionales de la vestimenta masculina (chupas, calzones) elaborados con algodón (pana). Id., Domingo Suárez de Velasco, Caja 973.

${ }^{23}$ Las abundantes piezas destinadas a cubrir la cama -colchas, jergones, almohadas,...están elaboradas con las fibras tradicionales, fundamentalmente: lana o lino y son más resistentes a la permeabilidad de las nuevas fibras. Pero, también a fines del XVIII ya se encuentran colchas de algodón pintado. Id., Domingo Suárez de Velasco, Caja 973.

${ }^{24}$ Frente a la abundancia de piezas (toallas, manteles, servilletas, paños de manos, etc.) que son fabricadas en lienzo y estopa, preferentemente, también a finales del siglo XVIII figuran en los inventarios toallas de algodón. Ibidem.

${ }^{25}$ Don Miguel Hernández de Medina fallece en 1799 y entre su ropa personal encontramos: calzones de pana negros y azules, pero también chalecos y chaquetas de algodón. Id., Félix González Mérida, Caja 867.

${ }^{26}$ Ver trabajos del grupo de investigación sobre el consumo ya citados anteriormente.

${ }^{27}$ Juan M. Bartolomé Bartolomé, El tránsito al crecimiento económico....

${ }^{28}$ A. Angulo Morales, ob. cit., p. 177.

${ }^{29}$ En Vitoria ya están presentes en la segunda mitad del siglo XVIII. Ibidem.

${ }^{30}$ Surge en Francia en 1700 y según Nuno Luís Madureira es la gran innovación del mobiliario del siglo de las luces. N. Luís Madureira, Lisboa 1740-1830. Cidade: Espaço e Quotidiano, Lisboa, Livros Horizonte, 1992, p. 183.

${ }^{31}$ Algunos autores han destacado su origen burgués y en concreto D. Roche se refiere a él como una pieza clave del mobiliario del pueblo de París en el siglo XVIII. D. Roche, Le peuple de Paris, París, Aubier Montaigne, 1981, pp. 149-150. 
una mayor gusto por el confort y el lujo, y que serán realizados con materiales más nobles ${ }^{32}$.

En cuanto a los útiles de cocina, frente a los más numerosos de carácter tradicional (calderas de cobre, tarteras y coberteras de hierro, sartenes, cazos, platos y fuentes de peltre, piedra o de cerámica de Talavera, etc. ${ }^{33}$ ), aparecerán también otros nuevos, sobre todo en la primera mitad del siglo XIX, los cuales nos informan sobre cambios relevantes en las costumbres y en la dieta alimenticia en la Edad Moderna: paso a una comida más individualizada, tal como preconizaban los manuales de urbanidad de los siglos XVII y XVIII, con un mayor uso de los platos, vasos, copas de cristal y los tenedores; uso útiles de asar los alimentos y particularmente parrillas, lo cual permitía variar la tradicional dieta consistente fundamentalmente en alimentos hervidos sobre la olla o caldera que descansaba directamente sobre las brasas o sobre unas trébedes ${ }^{34}$; la aparición del horno para asar también los alimentos y la elaboración de pan, pastas y bollos ${ }^{35}$. Tampoco faltarán los utensilios más conectados con el lujo u ostentación, como por ejemplo la tan valorada porcelana China ${ }^{36}$. Y finalmente, las chocolateras estarán siempre muy presentes ${ }^{37}$, a las que se unirán, aunque de forma muy excepcional, los molinillos de café $e^{38}$.

Como ya se ha señalado en el estudio cuantitativo, la valoración de los objetos destinados a la decoración de las casas ocupaba el último lugar, incluso por debajo de los escasísimos libros. No obstante, sus estancias estarán adornadas con abundantes cuadros y láminas donde predominará la temática de carácter religioso: retratos de santas y santos ${ }^{39}$ y también de advocaciones próximas a los

${ }^{32}$ Como por ejemplo los de Ramón Selva donde predomina el nogal y la caoba, A.H.P.L., Ildefonso García Álvarez, Caja 1167. Incluso, en el inventario de bienes de don José Fernández Chicarro figurarán los sofás. Id., Félix de las Vallinas, Caja 1137.

${ }^{33}$ Es característico el alto número de piezas de piedra que posee don José Fernández Chicarro, por ejemplo se van a inventariar 168 platos tasados cada uno a dos reales. Id., Félix de las Vallinas, Caja 1137.

${ }^{34} \mathrm{P}$. Manzanos Arreal, «La casa y la vida material en el hogar. Necesidades vitales y niveles de vida en la Vitoria del siglo XVIII», en la Vida cotidiana en Vitoria en la Edad Moderna y Contemporánea, J. Ma Imízcoz Beunza (dir.), San Sebastián, Txertoa, 1995, p. 206.

${ }^{35}$ En la familia Selva se mencionará en su inventario un horno de Periguela. A.H.P.L., Ildefonso García Álvarez, Caja 1167.

${ }^{36}$ Como los platillos y jarritas que aparecen en el inventario de don Ramón Selva. Ibidem.

37 Aparte de su gran valor dietético el chocolate se convierte también en una bebida indispensable de las reuniones sociales, donde las señoras y sus amigas que acuden a visitarla charlan mientras saborean el manjar del chocolate. P. Manzanos Arreal, ob. cit., p. 222.

${ }^{38}$ A diferencia de los hogares de la burguesía comercial vitoriana donde las cafeteras se normalizan desde mediados del siglo XVIII, en nuestro caso sólo hemos hallado una referencia a un molinillo de café en el inventario de don José Fernández Chicarro. A.H.P.L., Félix de las Vallinas, Caja 1137.

${ }^{39}$ Lo cual ya conocemos por el estudio pionero de A. Eiras Roel, «La burguesía mercantil compostelana a mediados del siglo XVIII: mentalidad tradicional e inmovilismo económico», en 
lugares de origen de la familia ${ }^{40}$. No faltarán, por otra parte, los velones, espejos y relojes de pared ${ }^{41}$ y la decoración de las paredes con cortinas cada vez más abundantes y elaboradas con fibras textiles de calidad ${ }^{42} \mathrm{o}$ bien con las nuevas: el algodón ${ }^{43}$.

Finalmente, sorprende la escasa, por no decir nula, presencia de libros en sus estancias, ya que, como hemos señalado, sólo en tres casos, dos de la familia Fernández Chicarro, aparecen algunos ejemplares de temática preferentemente religiosa: devocionarios y vidas de los $\operatorname{santos}^{44}$. No obstante, no apreciamos la tenencia observada en las familias vitorianas a favor de libros de historia o política en detrimento de los religiosos ${ }^{45}$.

En definitiva, en las familias de la burguesía comercial leonesa si observamos una mayor tendencia al confort, pero al igual que ocurría con la burguesía valenciana o vitoriana tampoco se puede hablar de un lujo exagerado ${ }^{46}$.

En la burguesía comercial con una orientación más financiera se reproduce en líneas generales el mismo esquema ya analizado de las anteriores familias burguesas, con la excepción más evidente de que los bienes destinados a la decoración de sus estancias son superiores a los de la otra burguesía y sobre todo se sitúan por encima de los útiles y el menaje de la cocina. Ahora bien, un estudio más detallado sobre todo de tipo cualitativo nos ofrece lo siguientes matices: en primer lugar, el capítulo de bienes de mayor valoración, joyas, alhajas, etc., se debe no tanto a los objetos destinados al adorno personal (pendientes, collares, alfileres, de oro, diamantes, etc.), lo cual sería más lógico dado el patrimonio de estas familias y la relevante posición social que ocupan ya en la primera mitad

Historia social de Galicia en sus fuentes de protocolos, Santiago, Universidad de Santiago, 1980. Y nos vuelve a reafirmar también Alberto Angulo Morales para la burguesía de Vitoria, ob. cit., p. 183. Y M. Bustos Rodríguez, ob. cit., para Cádiz.

${ }^{40}$ En los comerciantes de origen catalán no podía faltar Nuestra Señora de Montserrat. Don Ramón Selva tiene uno tasado en 20 reales. A.H.P.L., Ildefonso García Álvarez, Caja 1167.

${ }^{41}$ Como el de don Ramón Selva, con su caja pintada, tasado en 130 reales. Ibidem. Aunque, hay que precisar que éstas piezas no serán tan numerosas como en las familias vitorianas, donde los espejos comienzan a hacerse cada vez más habituales desde mediados del siglo XVIII y es muy numerosa la presencia de relojes de fábrica inglesa o francesa. A. Angulo Morales, ob. cit., pp. 179 y 184.

42 Así, por ejemplo, la familia Pablos Salán tiene a comienzos del siglo XIX, 1812, cuatro cortinas de esparragón (seda) para cubrir los balcones tasadas en 50 reales. A.H.P.L, Antonio Ginovés Martín, Caja 1011.

${ }^{43}$ La familia Selva decora las paredes tanto con cortinas de lienzo inglés como de algodón encarnado, floreado, etc. Id., Ildefonso García Álvarez, Caja 1167.

${ }^{44}$ Por otra parte, esta preferencia por la temática religiosa se observa también en Vitoria, donde representaba un 47,25\%. A. Angulo Morales, ob. cit., p. 198.

${ }^{45}$ Ibidem.

${ }^{46}$ R. Franch Benavent, ob. cit., p. 245; A. Angulo Morales, ob. cit., p. 324. 
del siglo XIX, como a las piezas de cubertería ${ }^{47}$. En segundo lugar, esta escasa tendencia hacia el lujo, la ostentación, se aprecia de nuevo en los textiles, donde sigue predominando en valoración la ropa de cama sobre la personal. No obstante, también es cierto que en la vestimenta personal ya son muy frecuentes las novedades en las prendas femeninas y masculinas: vestidos, chalecos, pantalones, elaborados con la nueva fibra del algodón. En tercer lugar, el mobiliario de la casa, aunque aumenta ligeramente su tasación respecto a la burguesía más comercial, sigue siendo muy abundante, tradicional y de escasa calidad ${ }^{48}$. En cuarto lugar, como ya se ha adelantado, una sugestiva novedad en el esquema general es la mayor valoración que tienen los objetos destinados a decorar las estancias de las casas, superando a los tradicionales útiles de cocina. De este modo, junto a las alfombras y alfombrillas sus paredes son cubiertas por abundantes cuadros de temática religiosa y también por cortinas, donde son frecuentes las de algodón y de colores, y los más novedosos espejos y relojes ${ }^{49}$. Y finalmente, la gran sorpresa es la ausencia total de libros, incluso los más necesarios para el desarrollo de sus negocios. En definitiva, unas condiciones o estilo de vida que nos denotan un lujo muy moderado y contenido, similar a lo que sucede incluso en la burguesía más potente gaditana ${ }^{50}$.

\section{CONDICIONES DE VIDA Y PAUTAS DE CONSUMO DEL CAMPESINADO LEONÉS DE TIERRA DE CAMPOS (COMARCA DE SAHAGÚN)}

Adentrarnos en la cultura material del campesinado de la Edad Moderna, incluso del siglo XVIII, constituye una tarea muy ardua debido al problema de las fuentes. No obstante, es necesario a nivel historiográfico abordar este tipo de estudios sobre los grupos no elitistas de la población pero en definitiva, no hay que olvidarlo, mayoritarios y menos homogéneos de lo que la visión tradicional historiográfica nos ha legado ${ }^{51}$.

${ }^{47}$ En el inventario de don José Fernández Llamazares las pieza de cubertería representan el $79,9 \%$ del total de las joyas y objetos de oro y plata. A.H.P.L., José Casimiro Quijano, caja 1202.

${ }^{48}$ En la sala principal de don José Fernández Llamazares junto a dos divanes, cuatro butacas y trece sillas, sólo figuran tres consolas de material noble, caoba, valoradas en 1500 reales. Ibidem.

${ }^{49}$ En la familia Llamas-Carcía Antón se tasa un reloj de música en 2.500 reales. Id., Ignacio Bayón Luengo, Caja 1129.

${ }^{50}$ M. Bustos Rodríguez, ob. cit., p. 240.

${ }^{51}$ Esta heterogeneidad de las comunidades campesinas ha sido señalada por P. Saavedra de tal forma que la desigual distribución de la propiedad y de la posesión de la tierra y los ganados se muestra más acusada en las comarcas de la meseta norte de España y en Tierra de Campos. P. Saavedra, «El campesinado en la España del A. Régimen: algunas consideraciones», en S. Castillo y R. Fernández (coord.), Historia social y ciencias sociales, LLeida, Milenio, 2001, pp. 225-246. 
El nivel medio de riqueza patrimonial del campesinado en la segunda mitad del siglo XVIII es de 9.863 reales. Se trata, por lo tanto, de un nivel de riqueza inferior, con más de 3.000 reales de diferencia, del de los campesinos leoneses de la Vega Baja del Esla ${ }^{52}$ e incluso de los de la zona de La Bañeza-Astorga ${ }^{53}$.

El análisis de la estructura interna de la riqueza patrimonial sigue otorgando, al igual que ocurría en los estudios comparativos, el primer puesto a las tierras de labor (tierras de cereal sobre todo de secano y viñedo), sin embargo, la importancia de dichos bienes raíces, con un 31,6\% de la riqueza patrimonial global, es de nuevo más bajo ${ }^{54}$, lo cual quizás pueda ser debido más que a unas explotaciones agrícolas inferiores a un menor precio de las tierras ante la mayor oferta del terrazgo productivo y la menor presión ejercida por la población, lo cual significaría unos valores de tasación de dichas tierras en los inventarios más bajos. También destaca la relevancia de los bienes mobiliarios ya que con el $27,7 \%$ de la riqueza patrimonial global se sitúan en un segundo lugar por encima de la valoración de las cabañas ganaderas y de las viviendas y dependencias complementarias ${ }^{55}$. Y finalmente, las viviendas y dependencias complementarias y la ganadería siguen ocupando un lugar destacado y con porcentajes, un $23,4 \%$ y un $17,3 \%$ respectivamente de la estructura global patrimonial, ya más similares a los comparativos leoneses. Esta importancia de las casas y viviendas complementarias se debe a los elevados porcentajes de posesión de casas y al alto valor de tasación de las mismas, ya que incluso entre el campesinado más pobre, por debajo de los 1.500 reales de riqueza patrimonial, es frecuente encontrar casas tasadas entre 250 y 440 reales $^{56}$. Aunque los inventarios postmorten son muy parcos en la información cualitativa si que podemos señalar que se trata de casas donde los niveles de riqueza establecen diferencias entre los campesinos más

${ }^{52}$ En 1730-59 la media de riqueza patrimonial se sitúa en 13.838 reales y en $1760-89$ se incrementa a 21.218 reales. J. M. Pérez García, «Evolución de los niveles de vida en la Vega Baja del Esla entre 1700 y 1850», en Un modelo social leonés en crecimiento: la Vega Baja del Esla entre 17000 y 1850, León, Universidad de León, 1998, p. 161.

${ }^{53}$ En 1750-60 estos niveles medios se sitúan en 13.136 reales para incrementarse también a fines del siglo en 21.031 reales. Juan M. Bartolomé Bartolomé, «Condiciones de vida y pautas del consumo del campesinado leonés de La Bañeza y Astorga (1750-1850)», en El Mundo Rural en La España Moderna, F. J. Aranda Pérez (coord.), Cuenca, Universidad de Castilla La-Mancha, 2004, pp. 589-590.

${ }^{54}$ En la Vega Baja del Esla oscila entre el $45,5 \%$ y el 43,4\% para la segunda mitad del siglo XVIII y La Bañeza-Astorga entre el $38,2 \%$ y el 46,2\%. Ibidem.

${ }^{55} \mathrm{Su}$ peso en la estructura de la riqueza global es mayor que en los casos de la Vega Baja del Esla y los de la Bañeza-Astorga donde en estas últimas zonas en 1750-60 con un 22\% se situaba en tercer lugar, descendiendo al $15 \%$ a fines del siglo. Aunque nunca hay que olvidar que sus medias familiares, 2.727 reales, siguen estando por debajo. Ibidem.

${ }^{56}$ Es lo que sucede, por ejemplo, con Manuel de la Fragua, vecino de San Pedro de Dueñas, el cual tiene una casa valorada en 440 reales, casi la mitad de su escaso patrimonio global de 937 reales. A.H.P.L., Juan Felipe y Godoy, Caja 4461. 
pudientes con casas de varios pisos y habitaciones espaciosas, divididas por tabiques de obra o cortinaje y las casas de lo más modestos o pobres, de un solo piso, con ventanas pequeñas para mantener el calor en invierno y preservarse de él en verano y estancias más pequeñas donde el hogar o cocina ocupaba un lugar preferencial, a veces único, no sólo para comer sino también para habitar y descansar (dormir junto al fuego) ${ }^{57}$. Además, es frecuente, lo cual también explica su alta tasación, que unido al hogar y cuartos de residencia estén también los edificios o estancias del corral, las caballerizas, los pajares, la bodega y a veces también el lagar ${ }^{58}$. Casas, en definitiva, construidas, principalmente las más modestas, a base de una estructura de madera que era rellenada con tapial (mezcla de barro y paja), ya que hasta el siglo XIX no se generalizan las casas de piedra o ladrill ${ }^{59}$.

En conclusión, se trata de un campesinado con unos niveles medios de riqueza patrimonial por debajo de sus homólogos leoneses ${ }^{60}$ y muy heterogéneo como lo demuestra el hecho de que únicamente el $42,2 \%$ de la muestra se sitúan entre el umbral de riqueza global de 1.500 reales y 5.000 reales $^{61}$, distribuyéndose el resto entre $4,5 \%$ por debajo de los 1.500 reales, el $22,2 \%$ de 5.000 a 10.000 reales, el $22 \%$ de 10.000 a 20.000 reales y el $8,9 \%$ por encima de los 20.000 reales.

Los bienes mobiliarios suponían un $27,7 \%$ del total de la riqueza patrimonial de nuestras familias campesinas, sin embargo, la media global de dichos bienes, 2.727 reales, exceptuando los animales domésticos, estaría de nuevo por debajo, aunque las diferencias sean más cortas, de los campesinos de la Vega Baja del Esla, La Bañeza y Astorga ${ }^{62}$. Si descendemos a un estudio más minu-

${ }^{57} \mathrm{Al}$ igual que ocurría en Vitoria, P. Manzanos Arreal, ob. cit., pp. 205-206.

${ }^{58}$ Por ejemplo, uno de los ricos campesinos con un valor patrimonial de 37.138 reales, Manuel Prieto, vecino de Sahagún, posee tres casas valoradas en 8.500 reales y todas ellas constan de cuartos altos y bajos, corral, caballerías, pajares y bodega. A.H.P.L., Juan Felipe y Godoy, Caja 4459.

${ }^{59}$ Bartolomé Yun Casalilla, «Peasant material culture in Castile 1750-1900 some proposals», en Material culture: consumption, life-style, standard of living 1500-1900, B4 proceedings Eleventh International Economic History Congress Milan, September 1994, A. Schuurman \& L. Walsh (eds.), pp. 127-130.

${ }^{60}$ Exceptuando el campesinado de El Bierzo donde en su zona de economía más vitícola, El Bierzo Bajo, no llegan a los 2.000 reales. Juan M. Bartolomé Bartolomé, Vino y viticultores ... op. cit., p. 211.

${ }^{61}$ Los cuales se pueden catalogar como patrimonios modestos, ya que poseen explotaciones agrarias dedicadas al cultivo del viñedo y cereal, vivienda y dependencias complementarias y una cabaña ganadera complementaria interesante. Es el caso, por ejemplo, de Manuel Conde Guaza, vecino de Sahagún, con un valor patrimonial global de 4.200 reales, que explota tierras de viñedo y cereal tasadas en 1.895 reales, tiene una casa valorada en 400 reales y una cabaña ganadera en 435 reales, consistente en un buey tasado en 250 reales, una cerda en 95 reales y una pollina en 90 reales. A.H.P.L., Juan Felipe y Godoy, Caja 4.459.

${ }^{62}$ En la Vega Baja del Esla en 1760/89 la media es 4.517 reales, pero en las zonas de Astorga-La Bañeza en 1750-60 la media es de 2.868 reales y en 1790-1800 de 3.184. J. M. Pérez García, ob. cit., p. 161. Juan M. Bartolomé Bartolomé, «Condiciones de vida...», pp. 592-594. 
cioso de la estructura interna de la riqueza mobiliaria podemos apreciar que sobresalen muy por encima de los demás los productos agrarios de la despensa con un $47,3 \%{ }^{63}$, lo cual nos indica una alta capacidad de producción agraria y una plenitud en las despensas campesinas terracampinas en la segunda mitad del siglo XVIII. Además, la relación de productos agrarios que figuran en los inventarios nos permite acercarnos, aunque sea tímidamente, a la comida de los campesinos. Así, más que carne de aves o de vacuno -sólo de forma muy esporádica aparece la cecina- $\mathrm{u}$ ovino lo normal era encontrar en dichas despensas productos derivados del cerdo (manteca, tocino, etc.) ${ }^{64}$. También aparece la harina aunque no especifica de que tipo de cereal, lo cual nos puede hacer pensar que el pan que consumían podría ser más que de trigo, destinado a pagar las rentas, de centeno, o de avena ${ }^{65}$. En el puchero diario no faltaban las legumbres tradicionales-titos, garbanzos, lentejas- no obstante, no encontramos en los inventarios las alubias $^{66}$ y tampoco figuran las patatas, aunque es probable que ya se sembrase este tubérculo de forma muy selectiva y no se declárese debido a ser un cultivo noval. Finamente, esta pobre dieta campesina era acompañada con el consumo de abundantes cantidades de vino, más en una zona donde la producción era significativa. No podemos proporcionar datos concretos del consumo pero dada la tónica general europea estaría por encima del litro diario por persona adulta ${ }^{67}$. Por último, hay que destacar que los bienes del ajuar, mobiliario de la casa, útiles domésticos, cuadros, libros, se sitúan en un segundo lugar de la riqueza mobiliaria con un $30,8 \%$ y 839 reales de media ${ }^{68}$. Este tipo de bienes son los que, por otra parte, como ya hemos señalado, nos dan a conocer las condiciones y el estilo de vida de la población campesina.

${ }^{63}$ Con 1.289 reales de media están por encima de las medias halladas en Astorga-La Bañeza y las de los años 1730-59 de la Vega Baja del Esla, siendo de nuevo superiores las de los años 1760/89. Ibidem.

${ }^{64}$ Las aves se consideraban en la Edad Moderna alimentos propios de príncipes y reyes. En cambio la carne del cerdo que hoza en el barro o los nabos que crecen bajo tierra se consideraban alimentos propios de vulgares campesinos. R. Sarti, Vida en familia, casa, comida y vestido en la Europa Moderna, Barcelona, Editorial Critica, 2002, p. 219.

${ }^{65} \mathrm{Al}$ igual que sucedía en el resto de Europa. Ibidem, p. 221.

${ }^{66}$ Las cuales se sumaron rápidamente a las legumbres conocidas tradicionalmente en Europa y con una aportación proteica a la dieta de los pobres muy importante. Ibidem, p. 231.

${ }^{67}$ El consumo del vino y cerveza estaba muy generalizado debido a varias razones: completaba el aporte calórico de la dieta, era difícil obtener agua potable, la creencia de que el agua era mala para la salud, la necesidad de facilitar la masticación y deglución del pan duro, el consumo de alimentos muy salados, y finalmente, permitía alcanzar un estado de euforia y excitación necesario para afrontar las inseguridades, los temores y las fatigas de la vida diaria, para ahuyentar el espectro o los retortijones del hambre. Ibidem, pp. 238-239.

${ }^{68}$ Porcentaje y media inferiores a las del campesinado de la Vega Baja del Esla -sobre todo en la muestra de los años 1760/89- y al de la La Bañeza-Astorga. J. M. Pérez García, ob. cit., p. 161. Juan M. Bartolomé Bartolomé, «Condiciones de vida...», pp. 594-597. 
Con el objetivo de poder aproximarnos al conocimiento de las condiciones de vida de las familias campesinas, hemos desglosado los bienes del ajuar, mobiliario, etc. en los mismos capítulos ya descritos de la burguesía. Junto al estudio cuantitativo nos adentraremos también en los aspectos cualitativos y trataremos de analizar las diferencias de acuerdo con la riqueza patrimonial global de las familias campesinas.

La estructura interna de este tipo de bienes mobiliarios es a primera vista muy similar a la del campesinado leonés de la Vega Baja del Esla, La BañezaAstorga, pero un estudio más profundo deja traslucir aspectos diferenciales: en primer lugar, la media de estos bienes, con 839 reales, es bastante modesta y en general está por debajo de la de los demás campesinos leoneses ${ }^{69}$. En segundo lugar, la relevancia de los textiles-ropa personal, de cama y casa- es todavía más fuerte, con un 65,3\% del valor de tasación de este tipo de bienes, que en el resto del campesinado leonés. En tercer lugar, dentro de este gran peso de los textiles sigue ostentando el lugar preferente -al igual que ocurre con el resto del campesinado leonés- el calzado y la ropa personal, pero la ropa de cama adquiere una importancia, con un 28\%, no conocida en los anteriores estudios comparativos, hasta el punto de que relega a un tercer puesto al mobiliario de la casa con un 19,2\%. En cuarto lugar, los objetos de decoración de la casa, que serán sobre todo religiosos, sólo serán valorados en una media de 25 reales $^{70}$. Y finalmente, el carácter más modesto de las condiciones de vida de este campesinado terracampino se vuelve a remarcar en la ausencia total de libros inventariados y en la escasa presencia de alhajas y objetos de oro y plata bien para uso personal o bien como cubertería ${ }^{71}$.

Ahora bien, las diferencias no sólo se aprecian en la visión genérica efectuada sino también y con mayor riqueza en un estudio más detallado. Así, ya hemos destacado la gran relevancia en la valoración, superando en la misma a los casos comparativos leoneses, del stock de productos textiles. Y dentro de los mismos como es el calzado y la ropa destinada a la vestimenta personal (interior y exterior) la mejor tasada, con 295 reales de media ${ }^{72}$, pero lo más novedoso es la

${ }^{69}$ Nos referimos a los mencionados de la Vega Baja del Esla y los de la zona La BañezaAstorga. Únicamente los campesinos de El Bierzo Bajo tendrán unas medias más bajas con 744 reales pero para todo el siglo XVIII. J. M. Pérez García, ob. cit., p. 167. Juan M. Bartolomé Bartolomé, «Condiciones de vida...», pp. 594-597; Ibidem., Vino y viticultores..., p. 364.

${ }^{70}$ Cantidades muy inferiores a los 308 reales de media de la zona de La Bañeza-Astorga. Juan M. Bartolomé Bartolomé, «Condiciones de vida... ob. cit.», pp. 595-598.

${ }^{71}$ Con el 0,3\% y una media de tan sólo 2,5 reales. En cambio en el campesinado de La Bañeza y Astorga este tipo de bienes adquirieron una gran importancia en el siglo XVIII con medias de 135 reales ya que se consideraban no sólo un distintivo de riqueza sino también una inversión segura ante las oscilaciones y devaluaciones monetarias. Ibidem.

${ }^{72}$ Aunque tenemos que precisar que no es extraño que en los inventarios no encontremos ningún elemento del vestir diario, ya que el difunto/a se llevaría a la tumba el único traje que poseía, sin embargo, la media también es inferior a la de La Bañeza-Astorga de 404 reales. Ibidem. 
importancia que adquiere la ropa de cama con 235 reales de media ${ }^{73}$. Aún podemos profundizar más si introducimos como nueva variable de análisis los niveles de patrimonio global del campesinado y la relación de los textiles con los mismos. De ese modo, las familias campesinas con los valores patrimoniales más bajos, inferiores a los 1.500 reales, su calzado y ropa personal es valorada en 165 reales de media, lo cual supone con el 61,3\% la cantidad más alta de este tipo de bienes, y en cambio la ropa de casa en tan sólo 25,5 reales de media, lo que significa un $9,5 \%$ de sus bienes mobiliarios analizados en este apartado ${ }^{74}$. En cambio, según va subiendo el nivel patrimonial global desciende la importancia porcentual del calzado y la ropa personal, aunque sigue ostentando el primer puesto, y se incrementa la de la ropa de casa y particularmente la de cama, hasta el punto de que en los patrimonios más solvente, por encima de los 20.000 reales la ropa personal significa el $21,8 \%$ de la estructura de los bienes y la ropa de cama el 33,3\% y una media de 608 reales frente los 397 de la ropa personal ${ }^{75}$.

Por lo tanto, se observan grandes contrates entre el propio campesinado en cuanto a la abundancia de piezas y calidad de las mismas de la ropa de casa y cama y sobre todo de la ropa destinada a vestir el cuerpo. Diferencias que, en definitiva como hemos apreciado anteriormente, guardan relación con el nivel de riqueza patrimonial global. De todas formas, sí podemos acercarnos al modelo genérico de vestimenta tanto de los hombres como de las mujeres. Así, en los varones como ropa interior encontramos las camisas ${ }^{76}$ de tejidos bastos como el lienzo. Y como ropa exterior: los calzones de paño, jubones de estameña, angua-

${ }^{73}$ Superior a los 163 reales de los campesinos de la zona de La Bañeza y Astorga. Ibidem.

${ }^{74}$ Es el caso, por ejemplo, de Manuel de la Fragua, vecino de San Pedro de Dueñas, con un valor patrimonial total de 937 reales, que posee una ropa personal tasada en 114 reales (consistente en una capa, dos anguarinas, jubón, ropilla, casaca, dos manteos, un rebociño y un par de zapatos) y en cambio la ropa de cama es más elemental y de ahí que tan sólo esté valorada en 33 reales (un jergón, una manta, y dos almohadas). A.H.P.L., Juan Felipe y Godoy, Caja 4461.

${ }^{75}$ Desequilibrio que en realidad no es tan fuerte debido a que en algunos inventarios de esta muestra no aparece ni se tasa la ropa personal. Aspecto al que no encontramos una explicación razonable ya que debido a su nivel alto económico de los difuntos es difícil que sólo posean la ropa personal con la que son enterrados o que ésta sea previamente vendida al inventario para recaudar dinero por el viudo/a De todas formas, como ejemplo tenemos el de Domingo Herrero Rojo, vecino de Calzada del Coto, con un valor patrimonial de 47.919 reales, cuya tasación de la ropa personal, con 572 reales (donde figuran mayor cantidad y calidad de las prendas de vestir, como capas de paño de Astudillo, etc.), se ve superada por la ropa de cama con 596 reales (once mantas de lana generalmente casera, cinco cobertores -dos de ellos de Palencia-, dos sábanas, tres almohadas, una colcha de gusanillo pintada, etc.). Y finalmente, también encontramos ropa de casa (tres tablas de manteles, cuatro servilletas) valorada en 53 reales. Id., Caja 4460.

${ }^{76}$ El uso de ropa interior, de lino o estopilla -el algodón tardará en introducirse hasta los años 30 del siglo XIX- es muy interesante de cara a la higiene personal consiguiendo reemplazar al agua debido a que cambiarse de camisa equivalía a nuestra ducha. P. Manzanos Arreal, ob. cit., p. 226. No aparecen, en cambio, los calzoncillos, únicamente hemos hallado tres pares de los mismos tasados en 18 reales en el inventario de Josefa Rodríguez, A.H.P.L., Antonio Mata, Caja 4464. 
rinas de paño, capas de paño, medias y zapatos de baqueta. En la mujeres, como ropa interior: calzones y enaguas y también camisas, generalmente de lienzo (estopa) y como externa: justillos, guardapiés, basquiñas, mantilla, jubones sin mangas, cuerpos, manteos, almillas, casacas, delantales, mantillas y para cubrir la cabeza: pañuelos de lienzo o seda. Todas las prendas están elaboradas utilizando en general como fibra textil el lino o la lana (estameña) ya que la más novedosa y relevante de cara a la modificación de las pautas de consumo: el algodón, no logrará abrirse hueco en estos medios rurales hasta la década de los años 30 del siglo XIX ${ }^{77}$.

Para concluir en este apartado de la ropa también resulta interesante remarcar que la ropa de casa empieza a figurar y se incrementa en el número de piezas y en calidad, por encima de los valores bajos de la media, particularmente en las familias campesinas de mayor riqueza patrimonial. Así, en sus ajuares encontramos servilletas (algunas de gusanillo), manteles (también de gusanillo), objetos de aseo: paños de manos y también artículos decorativos: las cortinas (generalmente de lienzo, o las más frecuentes de bayeta verde). Todo esto denota una mayor predilección por la comodidad y el lujo en el quehacer cotidiano.

En cuanto al mobiliario de la casa es desplazado, como ya hemos señalado, de su segundo puesto, como se apreciaba en los estudios comparativos de sus homólogos leoneses, a un tercer lugar con un 19,2\% y con una media por familia campesina de tan sólo 161 reales $^{78}$. De nuevo se vuelven a apreciar diferencias significativas entre las familias campesinas, las cuales vuelven a guardar una estrecha relación con los niveles de riqueza patrimonial global. De este modo, los campesinos más pobres, por debajo de los 1.500 reales de riqueza patrimonial sólo poseen unos bienes muebles, valorados en 53 reales de media, que quedan reducidos a la mínima expresión: pocas mesas y sillas, alguna cama acompañada de escasos bancos y escaños situados cerca del fuego para poder también utilizarlos como lugar donde descansar o dormir y, finalmente, algunas arcas para guardar desde productos de la cosecha -cereales, harina- o todo tipo de objetos variados ${ }^{79}$. Únicamente, los campesinos que podemos catalogar como medios, a

${ }^{77}$ Sólo en algunos inventarios, como el de Marcela Calvo, en 1776, aparece un pañuelo de algodón. AH.P.L., Antonio Mata, Caja 4461. Para una mayor información sobre las pautas de consumo y sus mutaciones sobre los productos textiles a partir de los años 30 del siglo XIX ver trabajos en España del grupo de investigación ya citado dirigido por el Dr. Bartolomé Yun Casalilla.

${ }^{78}$ Cuando en la zona de Astorga-La Bañeza es de 207 para los años finales del siglo XVIII y sobre todo en la Vega Baja del Esla es de 298,4 para los años 1760-89. Sólo el campesinado de El Bierzo Bajo tiene valores inferiores de 111 reales pero para todo el siglo XVIII. J. M. Pérez García, ob. cit., p. 265; Juan M. Bartolomé Bartolomé, «Condiciones de vida....», pp. 592-594; Idem, Vino y viticultores..., p. 364.

${ }^{79}$ Por ejemplo, Félix de la Fragua, vecino de la Grañeras, con unos bienes patrimoniales de tan sólo 786 reales, dispone únicamente de una mesa pequeña, tasada en tres reales, un arca grande valorada en 20 reales, dos bancos en tres reales y una cama de tablas viejas en ocho reales. 
partir de los 5.000 reales de riqueza patrimonial, superan la barrera de los 182 reales en mobiliario, lo cual indica mayor cantidad de piezas y de mayor calidad en la materia prima, más que mayor variedad ${ }^{80}$ y las familias campesinas con mayor riqueza patrimonial, más de 20.000 reales, consiguen amueblar sus estancias de la casa con un número de piezas mayor, de mejor calidad de la madera y sobre todo de mayor variedad, tasándose en una media de 409,5 reales ${ }^{81}$.

El menaje de la casa (loza fina, etc.) y los útiles de cocina (donde se incluyen también las calderas) ocupan el cuarto lugar de este tipo de bienes que estamos analizando con un 12,2\%. Sus valores medios familiares, 103 reales, se sitúan a nivel comparativo con sus homólogos leoneses por debajo de nuevo de los de la Vega Baja del Esla, pero muy por encima de los de la zona de AstorgaLa Bañeza ${ }^{82}$. No obstante, en este tipo de bienes tan básicos para las economías familiares también se apreciarán diferencias entre las familias campesinas pobres, por debajo de los 1.500 reales, donde únicamente poseerán los útiles más elementales de la cocina ${ }^{83}$, y las familias que superan la media de los 103 reales, pero aún así los contrastes son menores que en los anteriores bienes analizados ya que es cierto que los útiles tradicionales se convierten en más abundantes y de mejor calidad (calderas, cazos, sartenes, trébedes, etc., elaborados con cerámica de Talavera), sin embargo, no aparecerán de forma generalizada los nuevos instrumentos de asar la comida (asadores, parrillas, espeteras, etc. ${ }^{84}$ y tampoco

Lógicamente, ello guarda relación con su casa de un solo piso donde hay algún cuarto paro donde sobre todo la pieza más importante es la cocina. Este panorama tan pobre es el mismo que se dibuja para Vitoria. A.H.P.L., Juan Felipe y Godoy, Caja 4463. P. Manzanos Arreal, ob. cit., p. 212-214.

${ }^{80}$ Es el caso de Manuel del Corral, con 5.820 reales de media patrimonial, que posee seis arcas (dos grandes de nogal grande tasadas en ochenta y cuatro reales), dos escaños, cuatro bancos de respaldo, dos mesas, una cama torneada de haya tasada en 16 reales. A.H.P.L., Antonio Mata, Caja 4460.

${ }^{81}$ Aquí es donde junto a los anteriores muebles, pero más abundantes y de mayor calidad en la madera, nogal frente a la haya, etc., aparecen otros decorando las estancias de las casa que son signo de distinción y ostentación social. Así, en el inventario de Manuela de Saldaña, con una riqueza patrimonial de 81.146 reales y una tasación de los muebles de 705 reales, figuran piezas distintas destinadas a lograr una mejor decoración de las estancias y a su vez símbolo de una mayor ostentación: un velador de nogal, un bufete grande también de nogal valorado en cincuenta reales y un escritorio de nogal con ocho gavetas y sus portezuelas tasado en setenta reales. Ibidem.

${ }^{82}$ En la Vega Baja del Esla en el corte cronológico de 1760/89 el nivel medio es casi el doble, 191,6 reales, en cambio, en la zona de Astorga-La Bañeza no superan los 30 reales a finales del siglo XVIII. Ver J. M. Pérez García, ob. cit., p. 165; Juan M. Bartolomé Bartolomé, «Condiciones de vida...», pp. 594-597.

${ }^{83}$ Manuel de la Fragua, vecino de San Pedro de Dueñas, tiene una riqueza patrimonial de sólo 937 reales y su menaje y útiles de cocina que figuran en el inventario son únicamente: una caldera, una sartén, un cazo de azofar, tasado todo en 23 reales. A.H.P.L., Juan Felipe y Godoy, Caja 4461.

${ }^{84}$ Como ya se ha señalado en el estudio de la burguesía la aparición de estos útiles es muy relevante para poder estudiar los cambios en la dieta alimenticia de los hombres del A. Régimen, ya que la técnica más usada era la de hervir los alimentos en una olla o caldera, poniéndola 
abundarán en las familias campesinas de mayor nivel económico los útiles de cocina más vanguardistas y que denotan unas prácticas en la comida más individualizada (platos, vasos y sobre todo los tenedores) ${ }^{85}$.

Si nos adentramos en la decoración de las casas observamos las siguientes características: En primer lugar, un gran empobrecimiento, con tan sólo 25 reales de media, en relación con sus homólogos leoneses de la zona de La BañezaAstorga ${ }^{86}$. En segundo lugar, dentro de ese ambiente de escasez de objetos de adorno se aprecian de nuevo fuertes contrastes entre las familias campesinas más modestas, por debajo de los 5.000 reales, las cuales, no olvidemos, casi constituyen la mitad del campesinado con el 46,7\% de la muestra, y las más ricas, por encima de los 20.000 reales. Así, en las primeras lo más frecuente es que estos objetos decorativos, hasta los más frecuentes religiosos, brillen por su ausencia ${ }^{87}$. En cambio, en las segundas, las estancias son decoradas no sólo con los frecuentes cuadros de temática religiosa sino también con espejos en las paredes y velones ${ }^{88}$. Y finalmente, al igual que ocurría con otros grupos sociales de mayor nivel económico hay un predominio de los cuadros y estampas de carácter religioso $^{89}$.

También si establecemos la comparación con las familias campesinas de La Bañeza y Astorga sorprende la escasa presencia de las joyas de uso personal o

directamente sobre las brasas, que solían estar situadas en el centro de la cocina o sobre unas trébedes. Sin embargo, al construirse los hogares, a partir del siglo XVIII, contra la pared se abría la posibilidad de elevar los cacharros de cocina por encima del fuego y la instalación de asadores de hierro fundido con lo que se podían asar mejor los alimentos en vez de hervirlos. P. Manzanos Arreal, ob. cit., pp. 206-221.

${ }^{85}$ Sí que aparecen chocolateras, y vasos pero no hemos encontrado tenedores. El tenedor se hizo habitual a mediados del siglo XVIII dentro de la tendencia que imponían los manuales de urbanidad de prohibir el uso de los dedos y potenciar más el individualismo. Ibidem, p. 222.

${ }^{86}$ En estas familias campesinas las medias oscilan entre los 259 reales de los años 1750-60 y los 357 reales de los años 1790-1800. Juan M. Bartolomé Bartolomé, «Condiciones de vida..., pp. 594-597.

${ }^{87}$ Sólo en un número muy pequeño de familias aparecen cuadros y estampas religisosas colgadas de las paredes. Los ejemplos más extremos son los de Lorenzo Martínez, vecino de Sahagún, que con una riqueza patrimonial de 3.244 resales, en su inventario aparecen 20 cuadros, tasados en 81 reales, por encima del mobiliario de la casa, útiles de cocina y la ropa de la casa. Cuadros de temática preferentemente religiosa -Santa Marta, Santa Gertrudis, la Peregrina, La Magdalena, etc.- y dos de la calle de Santiago. Y Juana Santos, vecina también de Sahagún, que posee 24 cuadros valorados en 92 reales. A.H.P.L., Juan Felipe y Godoy, Caja 4461.

${ }^{88}$ Es lo que sucede con las estancias de Manuel Prieto, vecino de Sahagún, que tiene junto a los cuadros «un espejo mediano de los de Bilbao en veinte reales» y «un velón de alquimia mediano del cuatro mecheros en treinta reales». Id., Caja 4459.

${ }^{89}$ Apreciado también no sólo entre el campesinado sino con mayor profusión entre la burguesía llegando, por ejemplo en la burguesía compostelana, a convertir sus estancias en museos de arte sacro. A. Eiras Roel, «La burguesía mercantil...»; Juan M. Bartolomé Bartolomé, «El espejo de la emulación: condiciones de vida y pautas de consumo de la burguesía bañezana (17001850)» en El tránsito al crecimiento económico moderno..., pp. 31-51. 
cubertería $a^{90}$. Y finalmente, tampoco encontramos ningún tipo de libro en los inventarios de las familias campesinas terracampinas.

En definitiva, como conclusiones generales del campesinado podemos señalar las siguientes: Por una parte, se trata de unas familias campesinas donde los niveles de riqueza patrimonial global son en general inferiores a sus homólogos leoneses, lo cual determina el menor peso de las tierras de labor en dicha riqueza y la relevancia de los bienes mobiliarios. No obstante, por otra parte, esa riqueza mobiliaria de nuevo muestra un carácter más agrario, con un papel muy destacado de los productos agrarios de la despensa, lo cual se traduce a su vez en unas condiciones o estilo de vida más precarias que sus convecinos leoneses, sobre todo los de la Vega Baja del Esla y los de la zona Astorga-La Bañeza. De este modo, son los productos textiles, particularmente más la ropa destinada a la vestimenta personal y la de cama -con valores más altos en el último caso que los comparativos- que a la de casa, los que eclipsan a los demás bienes, especialmente a los más suntuosos: los destinados a la decoración de la estancias de la casa y a las joyas y alhajas bien de la cubertería o de uso personal. Y finalmente, al adentrarnos en la privacidad cotidiana de estas familias campesinas de Tierra de Campos, se aprecia una fuerte divergencia entre las mismas que guarda una relación muy directa con el grado de riqueza patrimonial global. De ahí, que esta diversidad del campesinado no se traduzca únicamente en el tamaño de las explotaciones agrarias y de su cabaña ganadera, sino también en sus condiciones y estilo de vida, en definitiva, en su privacidad cotidiana, orientada a una mayor comodidad y lujo, imitando lógicamente a los grupos sociales superiores sobre todo urbanos ${ }^{91}$, en las familias campesinas de mayor nivel económico.

${ }^{90}$ Mientras en las zonas de Astorga-La Bañeza los valores medios entre 151 y 184 reales en la segunda mitad del siglo XVIII. En cambio en las familias campesinas de Tierra de Campos, Sahagún y su zona, la media es de tan sólo 2,5 reales, la mayoría del campesinado no posee ningún tipo de joyas o alhajas, por debajo de los 10.00 reales de riqueza patrimonial, y únicamente por encima de los mencionados 10.000 reales figuran en los inventarios este tipo de bienes más suntuoso y de ostentación, pero de forma muy simbólica (una medalla de plata, un barquillo de plata), con 7,3 reales y 10 reales de media en los campesinos entre 10.000 y 19.999 reales y más de 20.000 reales respectivamente. A.H.P.L. (Protocolos Notariales de Sahagún).

${ }^{91}$ Según conocemos tanto a nivel europeo como en España estos procesos de emulación en las formas de vida, sobre todo las nuevas modas en la vestimenta, nuevas fibras textiles, etc., se producen de las zonas urbanas a las rurales y de los grupos de mayor categoría social y económica a los inferiores. Ver estudios sobre este apasionante tema del consumo de productos textiles a nivel internacional para Inglaterra de N. Mckendrick, «The Consumer Revolution of Eighteenth-Cenury England», en The Birth of a Consumer Society. The commercialization of Eighteenth-Century England, Londres, Europa Publications, 1982; P. Borsay, The English urban Renaissance. Culture and Society in the Provincial Town 1660-1770, Oxford, Oxford University Press, 1989; C. Shammas, The Pre-industrial Consumer in England and America, Oxford, Oxford University Press, 1990; L. Weatherill, Consumer Behaviour and Material Culture in Britain, 1660-1760, LondresNew York, Routledge, 1988. Para Francia, D. Roche, La culture des apparences. Une histoire du vêtement XVII-XVIII siècle, Paris, Fayard, 1989. Y en España los trabajos para Cantabria, Castilla y León del grupo de investigación ya citado coordinado por el Dr. Bartolomé Yun Casalilla. 
CUADRO 1.

BURGUESÍA COMERCIAL Y FINANCIERA

BALANCES PATRIMONIALES (REALES)

\begin{tabular}{lcccc}
\hline & $\mathrm{N}^{\circ}$ FAMILIAS & ACTIVO & PASIVO & LÍQUIDO \\
\hline Burguesía comercial & 11 & 5.545 .000 & 442.207 & 5.102 .793 \\
$\begin{array}{l}\text { Burguesía comercial } \\
\text { y financiera }\end{array}$ & 3 & 4.355 .738 & 1.674 .089 & 2.681 .649 \\
\hline
\end{tabular}

Fuente: A.H.P.L. (Protocolos Notariales)

CUADRO 2.

BURGUESÍA COMERCIAL Y FINANCIERA.

DINÁMICA DE LA REPRODUCCIÓN ECONÓMICA DE LAS FAMILIAS

A PARTIR DE LOS BIENES APORTADOS AL MATRIMONIO (REALES)

\begin{tabular}{|c|c|c|c|c|c|c|c|c|}
\hline & $\begin{array}{c}\mathrm{N}^{0} \\
\text { familias }\end{array}$ & $\begin{array}{c}\text { Bienes } \\
\text { aportados } \\
\text { esposo }\end{array}$ & $\begin{array}{c}\text { Bienes } \\
\text { aportados } \\
\text { esposa }\end{array}$ & $\begin{array}{l}\text { Total ambos } \\
\text { (A) }\end{array}$ & $\begin{array}{c}\text { Bienes } \\
\text { gananciales } \\
\text { (B) }\end{array}$ & $\begin{array}{c}\text { Total } \\
\text { patrimonial } \\
\text { (C) }\end{array}$ & $\% \mathrm{~A} / \mathrm{C}$ & $\% \mathrm{~B} / \mathrm{C}$ \\
\hline $\begin{array}{l}\text { Burguesía } \\
\quad \text { comercial }\end{array}$ & 8 & 668.860 & 413.736 & 1.082 .236 & 3.663 .516 & 4.745 .752 & 27,8 & 77,2 \\
\hline $\begin{array}{l}\text { Burguesía } \\
\text { comercial } \\
\text { y financiera }\end{array}$ & 3 & 1.290 .692 & 171.309 & 1.462 .001 & 2.777 .525 & 4.239 .526 & 34,5 & 65,5 \\
\hline
\end{tabular}

Fuente : A.H.P.L. (Protocolos Notariales)

CUADRO 3.

BURGUESÍA COMERCIAL Y FINANCIERA. DISTRIBUCIÓN RIQUEZA

PATRIMONIAL (En reales y porcentajes sobre el valor del stock de bienes inventariados)

\begin{tabular}{lcrcc}
\hline & $\begin{array}{l}\text { Burguesía comercial } \\
\text { (11casos) }\end{array}$ & $\%$ & $\begin{array}{l}\text { Burguesía comercial } \\
\text { y financiera (3 casos) }\end{array}$ & $\%$ \\
\hline Tierras de labor & 406.173 & 8 & 1.306 .651 & 30,6 \\
Vivienda y dependencias & & & & \\
$\quad$ complementarias & 871.033 & 17,1 & 407.546 & 9,5 \\
Ganadería & 17.018 & 0,4 & 43.230 & 1 \\
Bienes mobiliarios & 3.794 .513 & 74,5 & 2.507 .740 & 58,9 \\
\hline
\end{tabular}

Fuente : A.H.P.L. (Protocolos Notariales) 


\section{CUADRO 4. BURGUESÍA COMERCIAL Y FINANCIERA. DISTRIBUCIÓN RIQUEZA MOBILIARIA}

(En reales y porcentajes sobre el valor del stock de bienes inventariados)

\begin{tabular}{|c|c|c|c|c|}
\hline & \multicolumn{2}{|c|}{$\begin{array}{c}\text { Burguesía comercial } \\
\text { (11casos) }\end{array}$} & \multicolumn{2}{|c|}{$\begin{array}{l}\text { Burguesía comercial } \\
\text { y financiera ( } 3 \text { casos) }\end{array}$} \\
\hline & REALES & $\%$ & REALES & $\%$ \\
\hline Ajuar, mobiliario, joyas, etc. & 215.616 & 6 & 99.870 & 4,2 \\
\hline Deudas a favor del comercio & 1.306 .141 & 37 & 294.142 & 12,2 \\
\hline Géneros comercio & 1.261 .387 & 35,7 & 142.344 & 5,9 \\
\hline Dinero en efectivo (comercio) & 670.016 & 18,9 & & \\
\hline Dinero en efectivo & & & 733.597 & 30,5 \\
\hline $\begin{array}{l}\text { Cobrado letras, corresponsales, } \\
\text { etc. }\end{array}$ & & & 921.553 & 38,3 \\
\hline $\begin{array}{l}\text { Cobrado rentas, deudas a favor } \\
\text { de rentas, préstamos de dinero, } \\
\text { cereales y venta de productos } \\
\text { agrarios }\end{array}$ & 36.353 & 1,1 & 149.868 & 6,3 \\
\hline $\begin{array}{l}\text { Productos de la despensa y útiles } \\
\text { agrarios }\end{array}$ & 43.748 & 1,3 & 13.366 & 0,6 \\
\hline Acciones & & & 38.000 & 1,5 \\
\hline Coches diligencia & & & 15.000 & 0,5 \\
\hline
\end{tabular}

Fuente : A.H.P.L. (Protocolos Notariales)

\section{CUADRO 5. BURGUESÍA COMERCIAL Y FINANCIERA. CONDICIONES Y ESTILO DE VIDA}

(En reales y porcentajes sobre el valor del stock de bienes inventariados)

\begin{tabular}{|c|c|c|c|c|}
\hline & \multicolumn{2}{|c|}{$\begin{array}{c}\text { Burguesía comercial } \\
\text { (10 casos })\end{array}$} & \multicolumn{2}{|c|}{$\begin{array}{l}\text { Burguesía comercial } \\
\text { y financiera ( } 3 \text { casos) }\end{array}$} \\
\hline & REALES & $\%$ & REALES & $\%$ \\
\hline \multicolumn{5}{|l|}{ Decoración casa } \\
\hline (Objetos religiosos) & 4.538 & 2,4 & 6.577 & 7,1 \\
\hline Mobiliario casa & 23.116 & 12,3 & 17.497 & 18,9 \\
\hline \multicolumn{5}{|l|}{ Útiles cocina } \\
\hline (menaje loza fina) & 17.595 & 9,3 & 3.225 & 3,6 \\
\hline Ropa personal & 24.615 & 13 & 10.255 & 11,1 \\
\hline Ropa cama & 34.388 & 18,2 & 15.220 & 16,4 \\
\hline Ropa casa & 8.547 & 4,5 & 5.213 & 5,6 \\
\hline Joyas, etc. & 69.316 & 36,6 & 34.523 & 37,3 \\
\hline Libros, etc. & 7.063 & 3,7 & - & - \\
\hline
\end{tabular}

Fuente : A.H.P.L. (Protocolos Notariales) 


\section{CUADRO 6. \\ RIQUEZA PATRIMONIAL GLOBAL DE LAS FAMILIAS CAMPESINAS \\ DE LA COMARCA DE SAHAGÚN \\ (En reales y porcentaje sobre el valor del stock inventariado de bienes)}

\begin{tabular}{lrc}
\hline & Reales & $\%$ \\
\hline Tierras de labor & 140.500 & 31,6 \\
Vivienda y dependencias complementarias & 104.110 & 23,4 \\
Ganadería & 76.499 & 17,3 \\
Bienes mobiliarios & 122.709 & 27,7 \\
TOTAL & 443.818 & 100 \\
\hline
\end{tabular}

Fuente : A.H.P.L. (45 inventarios con los bienes tasados).

\section{CUADRO 7.}

DISTRIBUCIÓN DE LA RIQUEZA PATRIMONIAL MOBILIARIA.

FAMILIAS CAMPESINAS COMARCA DE SAHAGÚN

(En reales y porcentaje sobre el valor del stock inventariado de bienes)

\begin{tabular}{lrr}
\hline & Reales & $\%$ \\
\hline Aperos, útiles de labranza, cubas, etc. & 17.486 & 14,2 \\
Productos agrarios de la despensa (fibras textiles, etc) & 58.002 & 47,3 \\
Créditos, deudas a favor, dineros y alhajas & 9.449 & 7,7 \\
Ajuar, mobiliario, útiles domésticos, cuadros, libros & 37.772 & 30,8 \\
TOTAL & 122.709 & 100
\end{tabular}

Fuente : A.H.P.L. (45 inventarios con los bienes tasados).

CUADRO 8.

RIQUEZA MOBILIARIA CAMPESINADO DE LA COMARCA DE SAHAGÚN. VALORES MEDIOS FAMILIARES

\begin{tabular}{lr}
\hline & Reales \\
\hline Aperos, útiles de labranza, cubas, etc. & 389 \\
Productos agrarios de la despensa (fibras textiles, etc) & 1.289 \\
Créditos, deudas a favor, dineros y alhajas & 210 \\
Ajuar, mobiliario, útiles domésticos, cuadros, libros & 839 \\
TOTAL & 2.727 \\
\hline
\end{tabular}

Fuente : A.H.P.L.(45 inventarios con los bienes tasados). 


\section{CUADRO 9.}

CONDICIONES O ESTILO DE VIDA DE LAS FAMILIAS CAMPESINAS DE LA COMARCA DE SAHAGÚN

(En reales y porcentajes sobre el valor del stock inventariado de bienes)

\begin{tabular}{lrc}
\hline Bienes & Reales & $\%$ \\
\hline Decoración de la casa (objetos religiosos) & 1.125 & 3 \\
Mobiliario de la casa & 7.245 & 19,2 \\
Útiles cocina (menaje, loza fina, etc.) & 4.614 & 12,2 \\
Ropa personal & 13.295 & 35,3 \\
Ropa de cama & 10.566 & 28 \\
Ropa de casa & 785 & 2 \\
Joyas & 114 & 0,3 \\
Libros & 0 & 0 \\
TOTAL & 37.744 & 100 \\
\hline
\end{tabular}

Fuente : A.H.P.L. (45 inventarios con los bienes tasados)

CUADRO 10.

CONDICIONES O ESTILO DE VIDA DE LAS FAMILIAS CAMPESINAS DE LA COMARCA DE SAHAGÚN SEGÚN LOS NIVELES DE RIQUEZA PATRIMONIAL GLOBAL

(En reales y porcentaje sobre el valor del stock de bienes inventariado).

\begin{tabular}{|c|c|c|c|c|c|c|c|c|c|c|c|c|c|c|}
\hline \multirow[t]{2}{*}{ Reales } & \multicolumn{2}{|c|}{$\begin{array}{c}\text { Decoración } \\
\text { de la casa }\end{array}$} & \multicolumn{2}{|c|}{$\begin{array}{l}\text { Mobiliario } \\
\text { de la casa }\end{array}$} & \multicolumn{2}{|c|}{$\begin{array}{l}\text { Útiles cocina, } \\
\text { etc. }\end{array}$} & \multicolumn{2}{|c|}{$\begin{array}{c}\text { Ropa } \\
\text { personal }\end{array}$} & \multicolumn{2}{|c|}{$\begin{array}{c}\text { Ropa } \\
\text { de cama }\end{array}$} & \multicolumn{2}{|c|}{$\begin{array}{c}\text { Ropa } \\
\text { de casa }\end{array}$} & \multicolumn{2}{|c|}{ Joyas } \\
\hline & reales & $\%$ & reales & $\%$ & Reales & $\%$ & reales & $\%$ & reales & $\%$ & reales & $\%$ & reales & $\%$ \\
\hline .500 & 3 & 0,5 & 100 & 19,7 & 49 & 9 & 330 & 61,3 & 51 & 9,5 & 0 & 0 & 0 & \\
\hline $1.500-4.999$ & 237 & 3,3 & 1.560 & 21,7 & 1.041 & 14,5 & 2.889 & 40,3 & 1.412 & 19,7 & 38 & & 0 & \\
\hline $5.000-9.999$ & 301 & 3,1 & 1.816 & 18,8 & 1.104 & 11,4 & 3.087 & 32 & 3.097 & 32,1 & 238 & & 0 & \\
\hline $10.000-19.999$ & 354 & 2,7 & 2.125 & 16,2 & 1.309 & 10 & 5.402 & 41,3 & 3.575 & 27,3 & 253 & 1,9 & 73 & 0,6 \\
\hline+20.000 & 230 & 3,1 & 1.638 & 22,5 & 1.111 & 15,2 & 1.587 & 21,8 & 2.431 & 33,3 & 256 & 3,5 & 41 & 0,6 \\
\hline
\end{tabular}

Fuente : A. H.P.L. (45 inventarios con los bienes tasados). 